\title{
The role of the linker between the $\mathrm{SH} 2$ domain and catalytic domain in the regulation and function of Src
}

\author{
Stefania Gonfloni, John C.Williams ${ }^{1}$, \\ Katarina Hattula ${ }^{2}$, Albert Weijland ${ }^{3}$, \\ Rik K.Wierenga and Giulio Superti-Furga ${ }^{4}$
}

European Molecular Biology Laboratory, Meyerhofstrasse 1, D-69117 Heidelberg, Germany

${ }^{1}$ Present address: Howard Hughes Medical Institute, Department of Biochemistry and Molecular Biophysics, 630 W. 168th, Columbia University, NY 10032, USA

${ }^{2}$ Present address: Institute of Biotechnology, University of Helsinki, PO Box 45, FIN-00014 Helsinki, Finland

${ }^{3}$ Present address: Département Récepteurs et Protéines Membranaires, UPR 9050 du CNRS ESBS, Pôle Universitaire d'Illkirch,

Rue Sébastien Brandt, F-67400 Illkirch, France

${ }^{4}$ Corresponding author

e-mail: superti@embl-heidelberg.de

The crystal structures of the regulated Src and Hck tyrosine kinases show intramolecular interactions between the phosphorylated tail and the $\mathrm{SH} 2$ domain as well as between the $\mathrm{SH}$ 3omain, the $\mathrm{SH} 2$-catalytic domain linker (SH2-CD linker) and the catalytic domain. The relative contribution of these interactions to regulation of activity is poorly understood. Mutational analysis of Src and Lck revealed that interaction of the SH2-CD linker with the SH3 domain is crucial for regulation. Moreover, three sites of interaction of the linker with the catalytic domain, one at the beginning (Trp260) and two at the back of the small lobe, opposite the catalytic cleft $(\beta 2 / \beta 3$ loop; $\alpha C / \beta 4$ loop), impinge on Src activity. Other activating mutations map to the front of the catalytic domain in the loop preceding the $\alpha C$-helix ( $\beta 3 / \alpha C$ loop). SH2-CD linker mutants are deregulated in mammalian cells but transform fibroblasts weakly, suggesting that the linker may bind cellular components. Interpretation of our results on the basis of the crystal structure of Src favours a model in which the correctly positioned SH2-CD linker exerts an inhibitory function on catalysis of Src family members by facilitating displacement of the $\alpha C$-helix. This study may provide a template for the generation of deregulated versions of other protein kinases.

Keywords: Lck/protein kinase/regulation/Src/structure

\section{Introduction}

Since the discovery of $\mathrm{v}-\mathrm{Src}$ and $\mathrm{c}-\mathrm{Src}$ as the first protein tyrosine kinase and the first cellular protein tyrosine kinase respectively, a considerable research effort has focused on regulation of the cellular form as opposed to its deregulated viral counterpart (Varmus and Weinberg, 1993). In vertebrates, there are at least nine members of Src family kinases, all sharing a common architecture and overall regulation pattern (Superti-Furga and Courtneidge, 1995).
The domain structure of the Src family kinases comprises, from the $\mathrm{N}$ - to the $\mathrm{C}$-terminus, a region of $\sim 80$ residues termed the unique domain, an $\mathrm{SH} 3$ domain, an $\mathrm{SH} 2$ domain, a tyrosine kinase catalytic domain and a short stretch of residues called the tail. $\mathrm{SH} 3$ and $\mathrm{SH} 2$ domains are small protein-protein interaction modules often involved in signal transduction processes (Cohen et al., 1995; Pawson, 1995). Phosphorylation of a tyrosine residue (Tyr527 in chicken Src) in the C-terminal tail by tyrosine kinases of the Csk family dramatically reduces the activity of Src family members (Brown and Cooper, 1996; Lowell and Soriano, 1996). Mutation of this tyrosine residue or its dephosphorylation causes a several fold increase in activity (Hunter, 1987). All viral forms of Src lack the regulatory tyrosine in the tail (Jove and Hanafusa, 1987; Parsons and Weber, 1989). Active forms of Src, on the other hand, are phosphorylated at Tyr416 in the activation loop of the catalytic domain, mainly by autophosphorylation (Brown and Cooper, 1996).

An intramolecular regulation model for c-Src was proposed several years ago to account for the inhibitory role of Tyr527 phosphorylation and the presence of an SH2 domain (Matsuda et al., 1990). A large amount of evidence in favour of this model has since accumulated (Brown and Cooper, 1996). Besides the SH2 domain, the SH3 domain was also found to be absolutely required for regulation of Src (Murphy et al., 1993; Okada et al., 1993; Superti-Furga et al., 1993). Moreover, detailed mutational analysis of the regulatory role of the $\mathrm{SH} 3$ domain had shown a requirement for the hydrophobic residues of the ligand-binding surface (Erpel et al., 1995). A Src chimeric molecule bearing the $\mathrm{SH} 3$ domain of Fyn, but not that of Lck, was found to be perfectly regulated, indicating that the Lck SH3 domain was unable to recognize the cognate binding site on Src (Erpel et al., 1995).

The crystal structure of human Hck (Sicheri et al., 1997), human Src (Xu et al., 1997) and chicken Src (Williams, et al., 1997), all lacking the unique domain and regulated by $\mathrm{C}$-terminal phosphorylation, have been solved recently. These have provided a definitive molecular basis for the previous findings and have revealed some unexpected intramolecular interactions, bearing important consequences for Src regulation and function in the cell (reviewed in Mayer, 1997; Nguyen and Lim, 1997; Pawson, 1997; Shalloway and Taylor, 1997; Superti-Furga and Gonfloni, 1997). The SH2 and SH3 domains align at the 'back' of the catalytic domain, opposite the catalytic cleft, and the SH2 domain binds the regulatory tyrosine in the tail extending from the C-terminal part of the catalytic domain (see Figure 1B for illustration). A tripartite interaction between the $\mathrm{SH} 3$ domain ligand-binding surface, the linker connecting the $\mathrm{SH} 2$ domain to the catalytic domain (SH2-CD linker) and the back of the small lobe of the catalytic domain itself is observed in all 
A
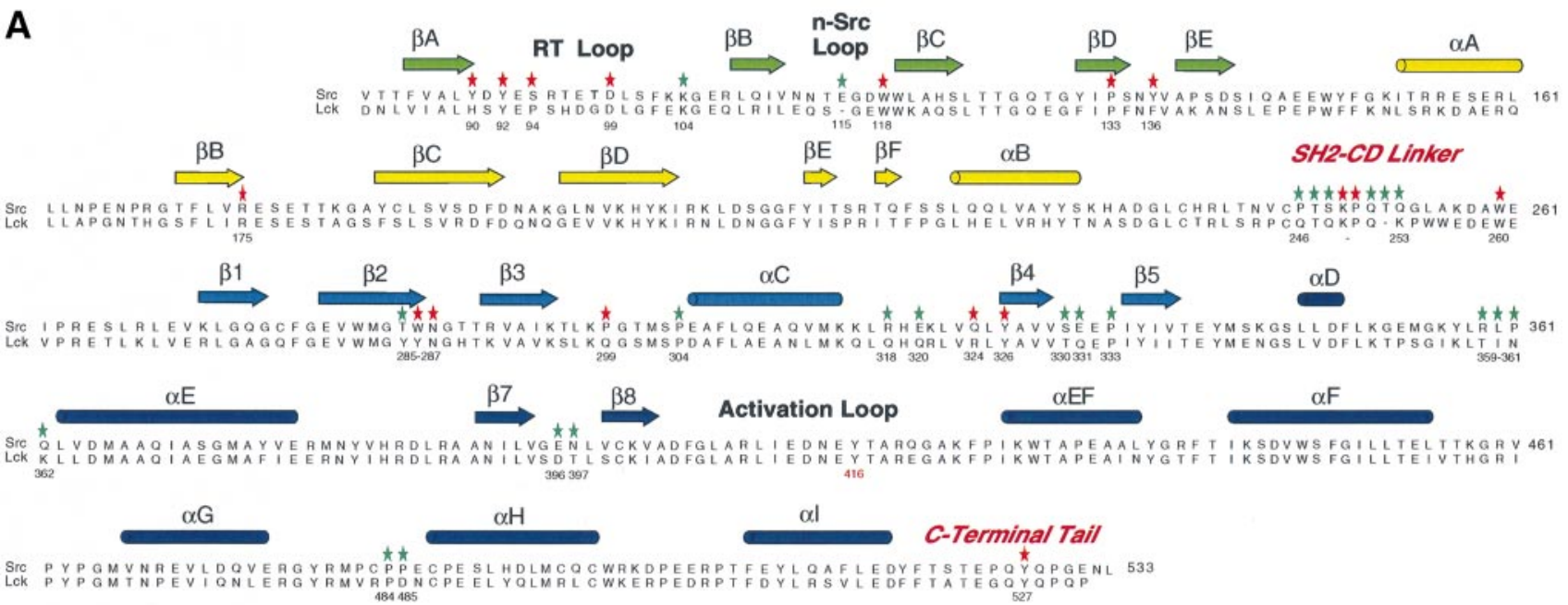

B

B SH2-CD Linker

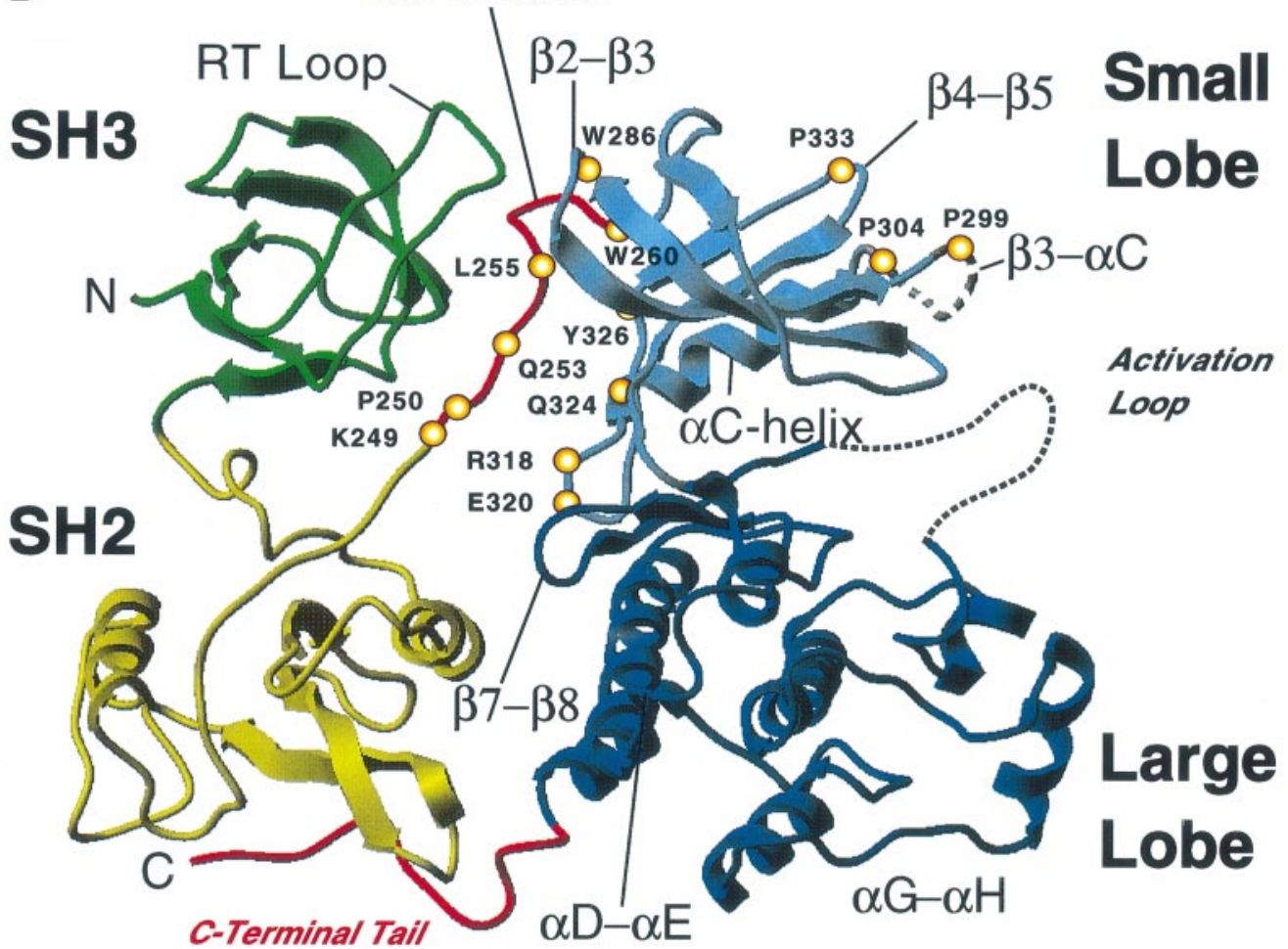

Fig. 1. Mutated regions mapped on the primary and tertiary structure of Src. (A) Sequence alignment of the chicken Src and human Lck proteins. The alignment was done using Pileup of the GCG package (University of Wisconsin). Elements of secondary structure are indicated over the Src sequence and refer to the crystal structure of regulated chicken Src (Williams et al., 1997). The elements are green for the SH3 domain, yellow for the SH2 domain and light and dark blue for the small and large lobes of the catalytic domain respectively. The unique domain, the structure of which is unknown, is not shown. Mutated residues are indicated by their number below the alignment. Tyr416, the site of phosphorylation in the activation loop, is designated in red. A star over a residue indicates if mutation of the residue impairs regulation (red) or is neutral (green). The same colour code is used in Figure 8. Mutations in the tail and in the SH3 and SH2 domains refer to previous work (Superti-Furga et al., 1993; Erpel et al., 1995). (B) Ribbon diagram of the regulated chicken c-Src structure. The same colour code is used as in (A). Only the most important residues discussed in this study are shown as yellow spheres. The figure was prepared using the ICM (Abagyan et al., 1994) and CANVAS programs. Structural elements relevant to the present study are indicated.

three structures. The SH2-CD linker appears to serve as an adaptor for the interaction of the SH3 and catalytic domains. A swung out position of the $\alpha \mathrm{C}$-helix in the catalytic domain is incompatible with catalytic activity. The $\alpha \mathrm{C}$-helix contains a conserved glutamate residue (the E of the PSTAIRE motif of cyclin-dependent kinases) that in active forms of kinases ion-pairs with Lys295 and aligns the lysine side chains so that it can coordinate phosphate groups of ATP (Taylor et al., 1993; Johnson et al., 1996). The activation loop, bearing the positive regulatory phosphorylation site (Tyr416), is not seen in its entirety in the three structures, but is thought to interact with and influence the configuration of the $\alpha C$-helix. Thus, the three structures show coupling of intramolecular interactions via the $\mathrm{SH} 2$ and $\mathrm{SH} 3$ domains and the catalytic potential of the kinase. Precisely how the SH3 and 
Table I. Identity and regulation properties of Src and Lck mutants

\begin{tabular}{|c|c|c|c|c|c|}
\hline Name & Mutation & Site & Character & Activity & $\begin{array}{l}\text { Regulation by } \\
\text { Csk }\end{array}$ \\
\hline \multicolumn{6}{|l|}{ Src mutants } \\
\hline c-Src wt (chicken) & & & & +++ & +++ \\
\hline Src-m1 & K249E,P250G & SH2-CD linker & Csk & +++ & - \\
\hline Src-m2 & P246K,T247R,S248N & SH2-CD linker & $\mathrm{Abl}$ & +++ & $++(+)$ \\
\hline Src-m3 & Q251T,T252V,Q253Y & SH2-CD linker & hu-Abl & +++ & $++(+)$ \\
\hline Src-m4 & substitution of 12 aa & SH2-CD linker & hu-Lck & +++ & $++(+)$ \\
\hline Src-m5 & W260A & end of linker & alanine & $++(+)$ & $+(+)$ \\
\hline Src-m6 & T285Y,W286Y & $\beta 2 / \beta 3$ loop & Lck & $++(+)$ & +++ \\
\hline Src-m7 & W286A,N287A & $\beta 2 / \beta 3$ loop & alanine & +++ & - \\
\hline Src-m8 & P299E,P304E & $\beta 3 / \alpha \mathrm{C}$ loop & Btk & +++ & - \\
\hline Src-m9 & P299E & $\beta 3 / \alpha \mathrm{C}$ loop & Btk & +++ & +++ \\
\hline Src-m10 & P299L & $\beta 3 / \alpha C$ loop & $\mathrm{v}$-Yes & +++ & +++ \\
\hline Src-m11 & P304E & $\beta 3 / \alpha C$ loop & Btk & +++ & ++ \\
\hline Src-m12 & R318Q,E320Q & $\alpha \mathrm{C} / \beta 4$ loop & hu-Lck & +++ & +++ \\
\hline Src-m13 & R318E,E320R & $\alpha \mathrm{C} / \beta 4$ loop & opp. charge & +++ & +++ \\
\hline Src-m14 & Q324E,Y326E & $\alpha \mathrm{C} / \beta 4$ loop & acidic & +++ & $+(+)$ \\
\hline Src-m15 & Q324R & $\alpha \mathrm{C} / \beta 4$ loop & hu-Lck & +++ & $+(+)$ \\
\hline Src-m16 & S330T,E331Q & $\beta 4 / \beta 5$ loop & Lck & +++ & +++ \\
\hline Src-m17 & P333G & $\beta 4 / \beta 5$ loop & Csk & +++ & ++ \\
\hline Src-m18 & R359N,L360V, P361N,Q362K & $\alpha \mathrm{D} / \alpha \mathrm{E}$ & mo-Lck & +++ & +++ \\
\hline Src-m19 & E396A,N397A & $\beta 7 / \beta 8$ loop & alanine & +++ & +++ \\
\hline Src-m20 & P484A,P485A,P488A & $\alpha \mathrm{G} / \alpha \mathrm{H}$ loop & alanine & + & +++ \\
\hline Src-m21 & P484D & $\alpha \mathrm{G} / \alpha \mathrm{H}$ loop & acidic & +++ & +++ \\
\hline Src-m22 & P485D & $\alpha \mathrm{G} / \alpha \mathrm{H}$ loop & acidic & +++ & +++ \\
\hline \multicolumn{6}{|l|}{ Lck mutants } \\
\hline Lck wt (human) & & & & +++ & +++ \\
\hline Lck-m1 & K232E,P233G & SH2-CD linker & Csk & +++ & - \\
\hline Lck-m2 & Q269E,P274E & $\beta 3 / \alpha \mathrm{C}$ loop & Btk & $++(+)$ & $(+)$ \\
\hline
\end{tabular}

Other mutants referred to in the text and in Figure 8 have been published previously (Superti-Furga et al., 1993; Erpel et al., 1995). Quantitation is done by calculating the doubling time of yeast cells after induction, and represents the average of at least three growth curve assessments.

SH2 domains achieve regulation of catalytic activity is not known.

We present here a mutational analysis of Src and Lck based partially on the crystal structure of regulated Src and partially on previous models. Our data indicate that the SH2-CD linker and the $\alpha \mathrm{C}$-helix in the catalytic domain are two critical players in the regulation of Src family kinases. At least three distinct interactions may couple the SH2-CD linker to orientation of the $\alpha \mathrm{C}$-helix. Several of the Src mutants are not only highly active but also transforming in murine fibroblasts, albeit with a reduced efficiency compared with Src mutated at the regulatory tyrosine. This suggests that the SH2-CD linker may interact with other proteins in mammalian cells.

\section{Results}

To test the functional role of the SH3 domain-mediated intramolecular interactions in kinases of the Src family, we have performed a mutational analysis of Src and Lck using the Schizosaccharomyces pombe regulation assay (Superti-Furga et al., 1993). The assay is based on inducible expression of c-Src in fission yeast, resulting in a cytotoxic phenotype proportional to Src activity and phosphorylation of yeast proteins on tyrosine. Co-expression of Csk reverts the lethal phenotype by phosphorylation of Tyr527 and repression of Src activity. The system has been used in the past to investigate structural requirements for Src regulation by C-terminal phosphorylation (Superti-
Furga et al., 1993; Erpel et al., 1995; Koegl et al., 1995; Weijland et al., 1997).

\section{The large lobe of the Src catalytic domain and the tail are sufficient substrate determinants for Csk}

In order for the S.pombe assay to be used to study residues important for intramolecular Src regulation, it is necessary for all mutants created to retain the ability to be phosphorylated at Tyr527 by Csk. Most of the Src mutants presented in this study map in the SH2-CD linker and the small lobe of the catalytic domain. We tested individually those alleles that were not regulated by Csk, for their ability to be phosphorylated by Csk (Src-m1, m5, m7, $\mathrm{m} 8, \mathrm{~m} 15$; Table I). Combination of these mutations with a kinase-inactivating mutation (K295M) and co-expression with Csk in yeast showed that these mutants were phosphorylated by Csk on tyrosine as well as kinase-inactive wild-type Src (data not shown). This was consistent with the possibility that the SH2-CD linker and the upper lobe of the catalytic domain are not required for Csk recognition and that the large lobe and the tail of Src are sufficient substrate determinants for Csk. We tested this hypothesis by expressing three different forms of kinase-inactive Src as GST fusions in yeast and assaying the ability of Csk to phosphorylate the fusion proteins (Figure 2). GST-Src$\Delta \mathrm{U}^{-\mathrm{kin}^{-}}$contained Src residues starting from Gly81, just lacking the unique domain, GST-Src-KO-kin- contained the catalytic domain starting at Asp258 and GST-Src-LLkin $^{-}$contained just the large lobe of the catalytic domain 


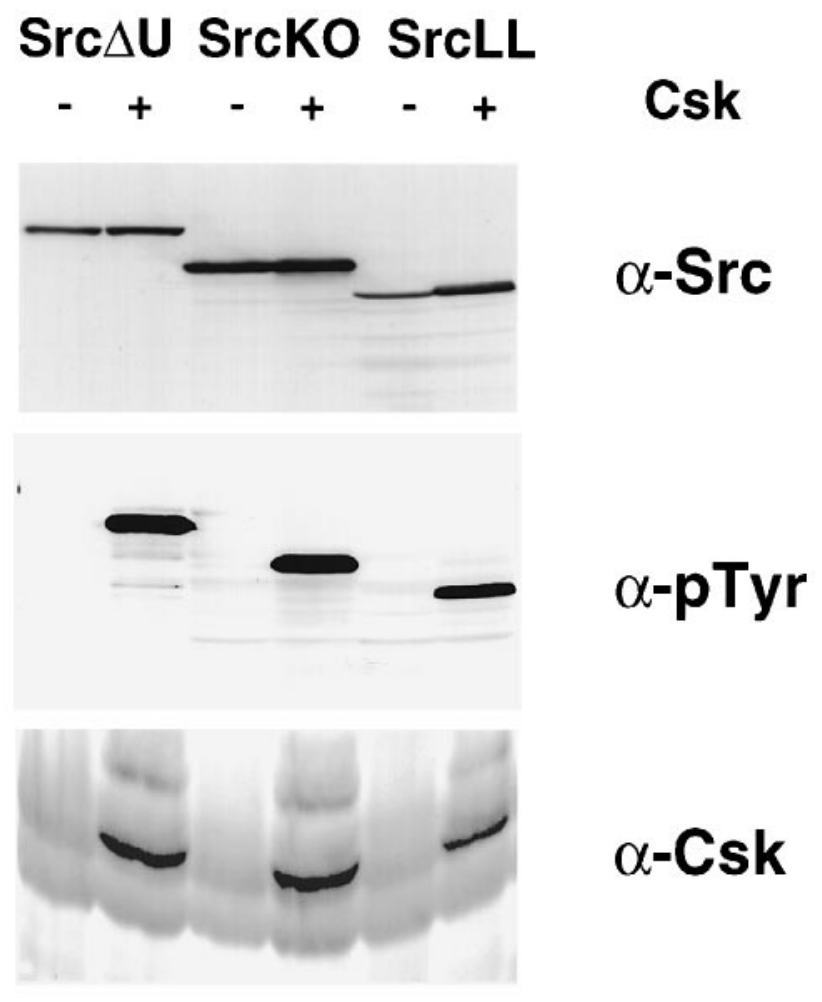

Fig. 2. The large lobe and tail of Src are Csk substrates. Extracts of S.pombe cells co-transformed with pAG-Src- $\Delta \mathrm{U}_{-} \mathrm{kin}^{-}$, pAG-Src-KO$\mathrm{kin}^{-}$or pAG-Src-LL-kin ${ }^{-}$and either pRSP or pRSP-Csk were analysed by polyacrylamide gel electrophoresis followed by immunoblotting, and probed with antibodies specific for the C-terminal region of Src (upper panel), for phosphotyrosine (middle panel) or for the C-terminal region of Csk (lower panel). Expression of Csk was induced by removal of thiamine from the medium. Cell extracts were generated $16 \mathrm{~h}$ after induction.

starting at residue Met341. All three proteins accumulated at comparable levels. In the absence of Csk induction, no phosphorylation on tyrosine was detectable. When Csk was induced, similar levels of phosphorylation on tyrosine were detected in all the three cases. This result suggested that the large lobe and tail region of Src are sufficient substrate determinants of Csk.

\section{Mutations in the SH2-CD linker deregulate Src and Lck}

The structures of regulated Src and Hck show that the 15 residue long linker connecting the $\mathrm{SH} 2$ domain and the catalytic domain forms an extended structure sandwiched between the SH3 domain and the catalytic domain (Sicheri et al., 1997; Williams et al., 1997; Xu et al., 1997; see Figure 1B). To test if the linker is involved in regulation, we have mutated Lys249 and Pro250 to Glu and Gly respectively, the residues of Csk (Src-m1; Table I). A proline at position 250 is found in all members of the Src, Abl and Btk families, while lysine at position 249 is conserved among most Src and Abl family members. Src$\mathrm{m} 1$ was tested in the S.pombe assay (Superti-Furga et al., 1993), along with wild-type Src as control (Figure 3A and B). Src-m1 protein accumulated to normal levels, was active and caused extensive phosphorylation of endogenous proteins, resulting in growth arrest and death of the cells. However, in contrast to wild-type Src, the activity of Src-m1 was not regulated by Csk, as judged by the growth curve (Figure 3A) and the level of proteins phosphorylated on tyrosine (Figure 3B). To test the involvement of other residues of the linker, we mutated the three residues preceding or following the conserved lysine and proline to the residues of Abl (Src-m2 and Src$\mathrm{m} 3$, Table I). Both alleles were regulated by Csk (Figure $3 \mathrm{~A}$ and B only data for Src-m3 shown). This was a surprising result since the mutations were all non-conservative in character. Finally, we exchanged 12 residues from the linker region of Src with the corresponding residues of Lck (Pro246 to Lys257, Src-m4; Table I). From the conserved cysteine (Cys245 of Src) to the conserved aspartate (Asp258), the Lck linker is one residue shorter and shares only four identical residues with Src (Figure 1A). Again surprisingly, Src-m4 was not seriously impaired in regulation, indicating that the Lck linker can substitute for the linker of Src (Figure 3A and B).

To test involvement of the linker in regulation of Lck itself, we first tested wild-type Lck in the yeast assay. Lck expression caused a cytotoxic phenotype that was very similar to the one observed with Src and Fyn (Figure 3A and $\mathrm{B}$ and data not shown), and was reverted by Csk (Figure 3A and B). Mutation of the conserved lysine and proline to glutamate and glycine, corresponding to the Src-m1 mutation, abolished Lck regulation (Lck-m1; Figure 3B). Together, these results indicate that the SH2$\mathrm{CD}$ linker is a crucial element in conveying regulation by C-terminal phosphorylation in kinases of the Src family. At the same time, the results suggest that the linker of Src and Lck, and possibly also of Abl, have a compatible structure and function.

\section{Tryptophan 260 at the end of the SH2-CD linker is involved in regulation}

Trp260 of Src is highly conserved among protein tyrosine kinases. In the structure of Src and Hck, Trp260 is located at the boundary between the SH2-CD linker and the catalytic domain, and its side chain is directed towards the $\alpha \mathrm{C}$-helix (Figure 1B). Kuriyan and colleagues have proposed that Trp260 may be instrumental in coupling the SH2-CD linker conformation to the orientation of the $\alpha \mathrm{C}$ helix, and thus may be a key regulatory component (Sicheri et al., 1997). To test this hypothesis, we mutated Trp260 to alanine and analysed the resulting allele in the yeast regulation assay (Src-m5, Figure 3A and B). Src-m5 accumulated normally and displayed a growth-inhibitory ability that was only slightly reduced compared with wildtype Src (Figure 3A). Possibly, this may reflect a structural role for Trp260. However, Src-m5 was as active as Src, judging by the ability to cause phosphorylation of yeast proteins (Figure 3B). The presence of Csk led to only a moderate repression of activity of Src-m5, as observed in the very sensitive growth assay (Figure 3A), and hardly any reduction in the degree of phosphorylation of yeast proteins (Figure 3B). Thus Trp260 is necessary for Src regulation, in agreement with its proposed role.

\section{Mutations in the back of the catalytic domain impair Src regulation}

The SH2-CD linker also interacts with the small lobe of the catalytic domain (Sicheri et al., 1997; Williams et al., 1997; Xu et al., 1997). A prominent interaction appeared to be hydrophobic stacking of Leu255 with a binding 

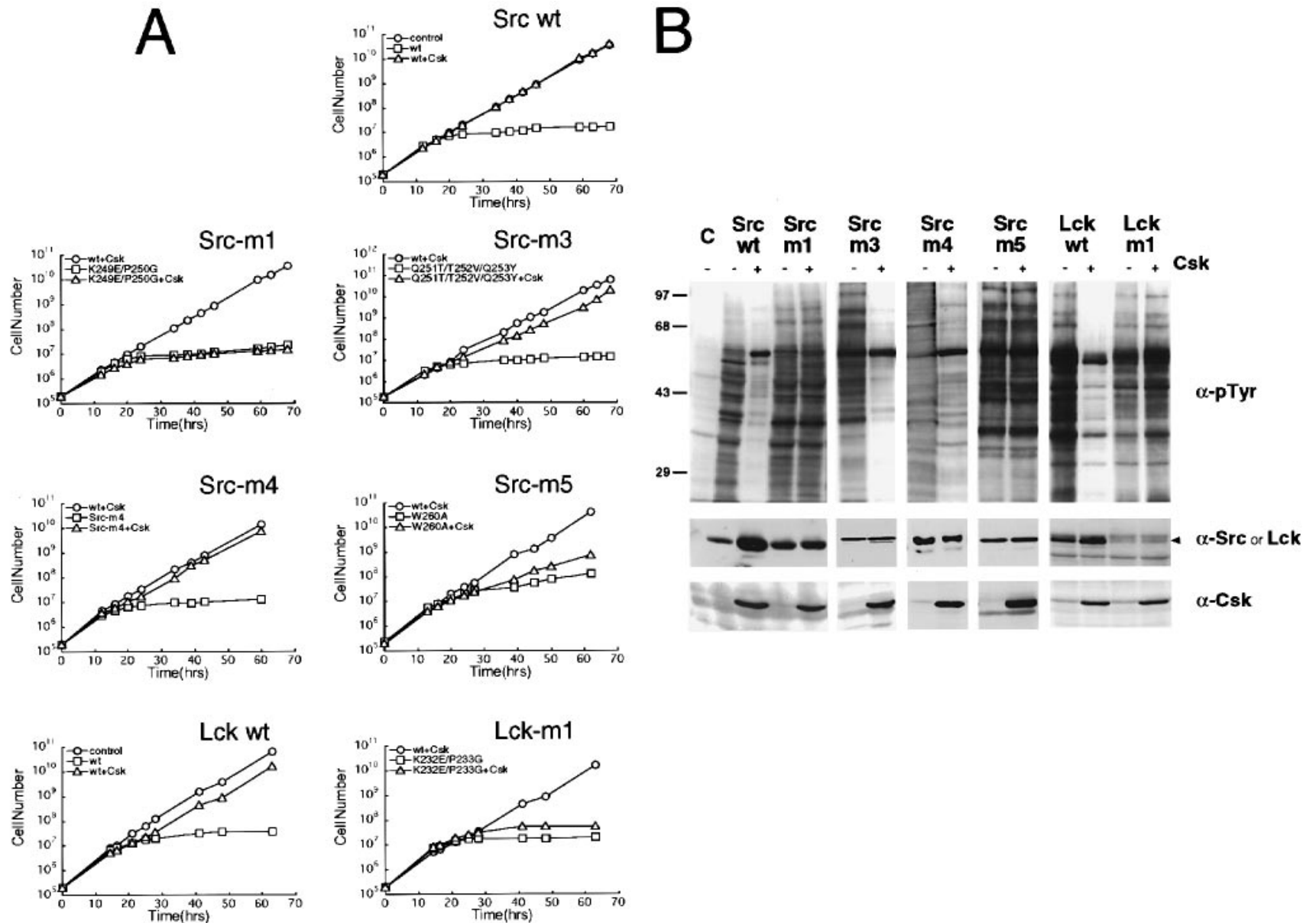

Fig. 3. Mutations in the SH2-CD linker region of Src and Lck. (A) Growth curves of S.pombe cells expressing various Src or Lck alleles from pRSP (as indicated) and pAU or pAU-Csk. Control cells are transformed with the two empty vectors. For induction, cells were washed to remove thiamine. At different time points post-induction, a sample was taken and cell number determined. At least three different colonies were tested independently. A representative growth curve is shown. The $y$-axis is logarithmic. Under the conditions used, expression of Src and Lck takes $\sim 18 \mathrm{~h}$ post-induction to become maximal. (B) Immunoblot of lysates prepared from S.pombe cells expressing Src mutants. For each sample, the same amounts of extracts were resolved by SDS-PAGE and probed with antibodies specific for phosphotyrosine (upper panel), for the N-terminal region of Src or the C-terminal region of Lck (middle panel), or for the C-terminal region of Csk (lower panel). The arrowhead points to migration of the Lck protein.

pocket formed by the side chains of Trp286 in the $\beta 2 / \beta 3$ loop and Tyr326 in the beginning of the $\beta 4$ strand (Figure 1B). Asn287, the residue immediately following Trp286 in the $\beta 2 / \beta 3$ loop, forms a weak hydrogen bond with Arg95 in the RT loop of the SH3 domain. Mutation of Trp286 and Asn287 to alanine (Src-m7) resulted in a Src protein that was normally active but almost completely refractory to regulation by Csk, judging by both the growth curve and the levels of tyrosine phosphorylation (Figure $4 \mathrm{~A}$ and $\mathrm{B}$ ). This suggests that interactions with the $\beta 2 / \beta 3$ loop are decisive for regulation. Because we previously had observed regulation of a Src allele bearing mutation of Arg95 in the RT loop (Erpel et al., 1995), we believe that mutation of Trp286, more than mutation of Asn287 in the same allele, may account for the observed impairment of regulation.

Lck has two tyrosines at the position corresponding to Trp286. We wanted to test whether these tyrosines could substitute for the corresponding Src residues or if their absence may account for the observed lack of regulation of a Src chimera bearing the Lck SH3 domain (Erpel et al., 1995). Src-m6 (T285Y,W286Y) was active and perfectly regulated by Csk (Table I; data not shown), suggesting that tyrosine at position 286 can substitute for Trp286 of Src.

We changed Tyr326 in the beginning of $\beta$-strand 4 and Gln324 in the $\alpha C / \beta 4$ loop to glutamate (Src-m14). Tyr326 not only forms the lower part of the hydrophobic pocket, but also interacts with $\mathrm{Arg} 95$ in the SH3 domain (Xu et al., 1997) and with Gln251 in the linker (Williams et al., 1997). Likewise, Gln324 forms multiple hydrogen bonds with the linker (Sicheri et al., 1997; Williams et al., 1997; Xu et al., 1997). Src-m14 accumulated well, was active but was only poorly regulated by Csk (Figure 4A and B). At position 324, Lck has Arg instead of Gln (Figure 1A). To detect key differences between Src and Lck (see above), we generated the Src-m15 allele (Q324R). The corresponding protein was active but severely impaired in regulation, to a degree comparable with Src$\mathrm{m} 14$ (Figure 4A and B).

Together, this indicates that at least two sorts of interactions of the linker with the back of the catalytic domain are essential for proper regulation to occur. One interaction is with the hydrophobic binding pocket. Another interaction involves the linker and $\mathrm{Q} 324$ in the $\alpha \mathrm{C} / \beta 4$ loop. 
A
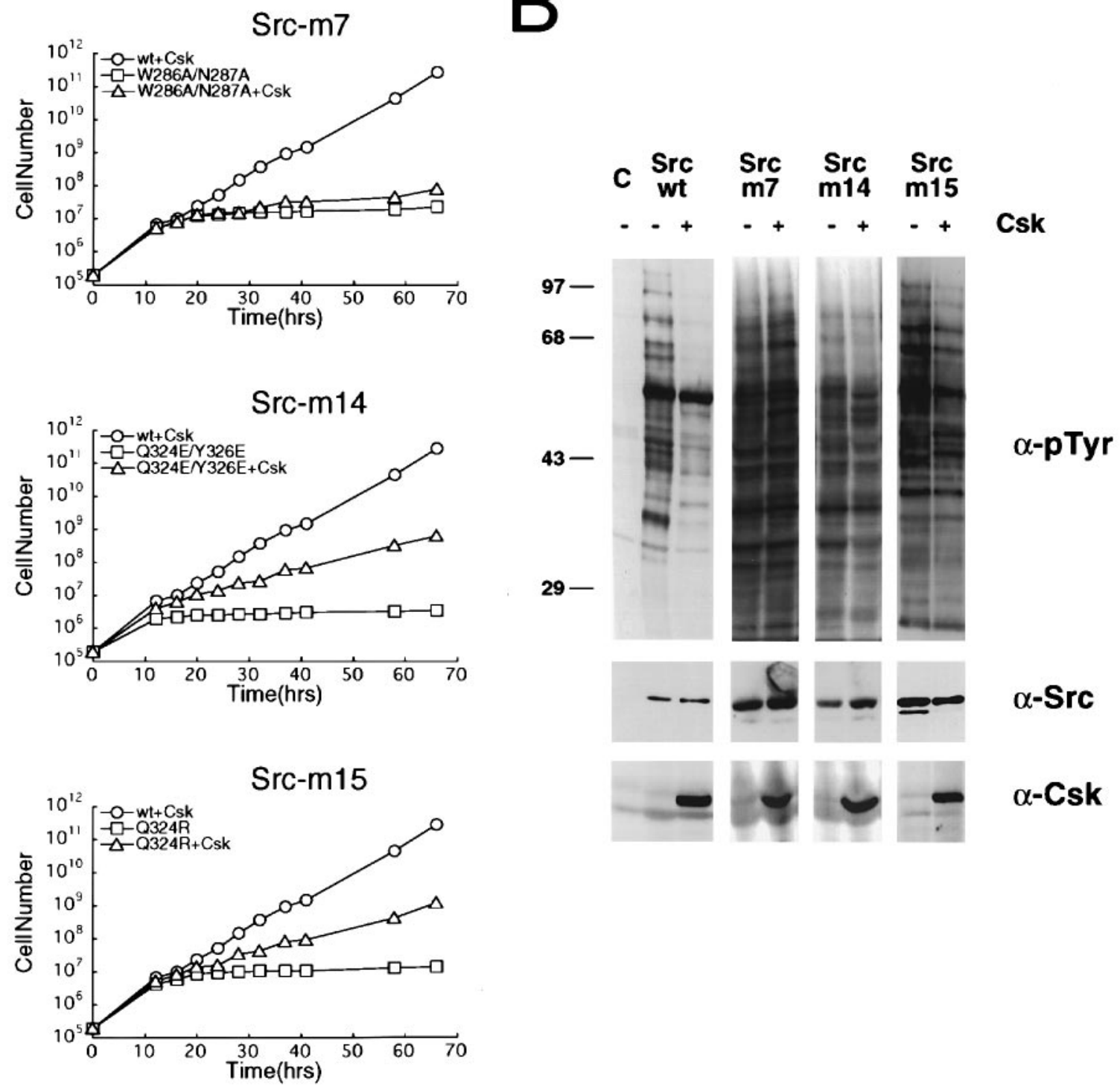

B

Fig. 4. Mutations in the back of the catalytic domain of Src. (A) Growth curves of S.pombe cells expressing three mutants that map in the linkerinteracting surface on the catalytic domain. Src expression (from the pRSP vector) was induced by thiamine deprivation. Samples were treated as described in Figure 3A. (B) Immunoblot of lysates prepared from cells expressing Src mutants. Extracts of the same cells as above were analysed as described in Figure 3B.

\section{Not all linker interaction sites are essential for regulation}

In a screen originally designed to identify the putative SH3 domain interaction site, we have mutagenized several regions of Src based on the common and different regulation features of Src family kinases (Erpel et al., 1995) and the structure of the catalytic domain of the insulin receptor (Hubbard et al., 1994). All mutations mapping to the large $\mathrm{C}$-terminal lobe of the catalytic domain were neutral (Src-m18, $\alpha$ D/ $\alpha$ E loop; Src-m19, $\beta 7 / \beta 8$ loop; Src$\mathrm{m} 20-22, \alpha \mathrm{G} / \alpha \mathrm{H}$ loop). Among the alleles that were well regulated is Src-m12 (R318Q,E320Q; data not shown, Table I). This was surprising since the structure shows that Glu320 points towards the linker, and $\operatorname{Arg} 318$ hydrogen-bonds with both the linker and the SH3 domain (Sicheri et al., 1997; Williams et al., 1997; Xu et al., 1997). To test the role of these residues further, we switched their charges (R318E,E320R; Src-m13), but again the protein was active and regulated by Csk (Table I, data not shown). Arg318 is therefore not a key component of the regulatory interactions and not all linker interactions seen in the crystal structure affect Src regulation. In Figure 8, all regions mutated and found not to be involved in regulation are highlighted in green.

\section{Mutations in the $\beta 3 / \alpha C$ loop affect Src activity and regulation}

Mutation of two prolines in the $\beta 3 / \alpha C$ loop of Src into glutamic acid, the residues of Btk (P299E,P304E; Src$\mathrm{m} 8$ ), yielded a Src protein that was at least as active as wildtype c-Src but completely unaffected by co-expression of Csk, judging by the abilities both to inhibit yeast growth and to cause phosphorylation of endogenous proteins (Figure 5A and B). The proline residue of chicken c-Yes corresponding to Pro299 is mutated to leucine in the viral gene (Sudol et al., 1988). To test the individual role of 
A
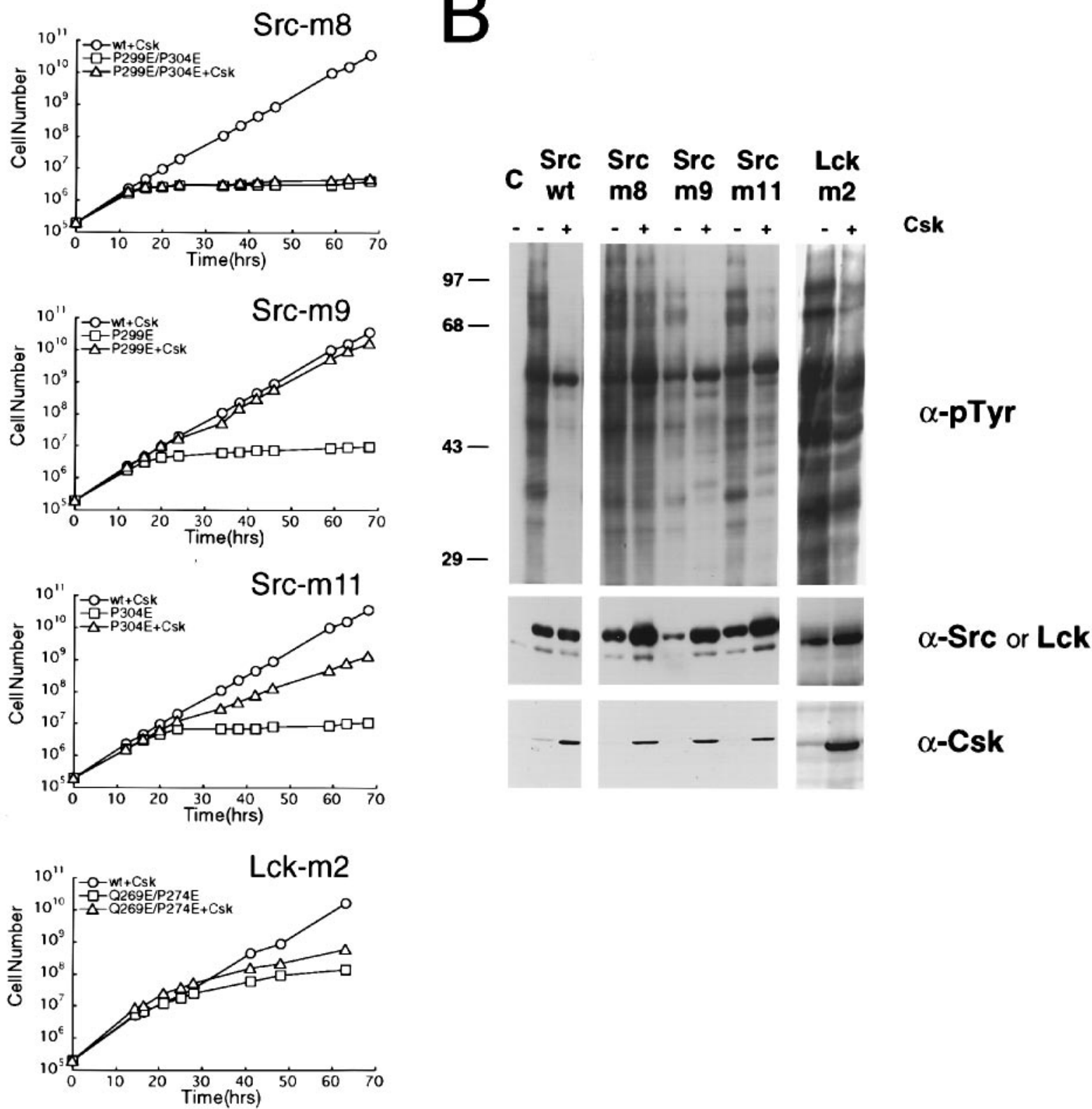

Fig. 5. Mutation of the $\beta 3 / \alpha \mathrm{C}$ loop of Src and Lck. (A) Growth curves of S.pombe cells expressing Src or Lck mutants that map in the catalytic domain (from pRSP). Samples were treated as described in Figure 3A. (B) Immunoblot of lysates prepared from cells expressing Src or Lck mutants. Extracts of the same cells as above were analysed as described in Figure 3B.

Pro299, it was mutated to either glutamic acid, as in Src$\mathrm{m} 8$ (P299E, Src-m9), or to leucine, as in v-Yes (P299L; Src-m10). Both proteins were regulated well (only data for Src-m9 shown, Figure 5A and B). Individual mutation of Pro304 to glutamic acid (P304E; Src-m11) resulted in a protein that was affected in its ability to be regulated by Csk, albeit not nearly as strongly as Src-m8 (Figure $5 \mathrm{~A}$ and $\mathrm{B})$. These results suggested that simultaneous mutation of Pro299 and Pro304 to glutamic acid was necessary to obtain deregulation of Src. To test whether the $\beta 3 / \alpha C$ loop was affecting regulation of other Src family members, we made the mutation corresponding to Src-m8 in Lck (Q269E,P274E; Lck-m2). Regulation of Lck-m2 was severely impaired, indicating that the conformation of the $\beta 3 / \alpha \mathrm{C}$ loop affected regulation of all $\mathrm{Src}$ family members (Figure 5A and B). It is not yet known if the $\mathrm{SH} 3$ domain interaction in these mutants is affected or not.

\section{SH2-CD linker and kinase domain mutants are deregulated and transforming in mammalian cells} The S.pombe expression system is a reliable assay for the structural requirements of Src regulation by C-terminal phosphorylation but does not allow for testing of a specific Src structure in signal transduction or cellular transformation. SH3 mutants of Src, for example, that are not regulated by Csk in the yeast assay, are also deregulated in mammalian cells, but fail to transform fibroblasts (Erpel et al., 1995) or transduce mitogenic signals efficiently (Broome and Hunter, 1996; Erpel et al., 1996). To test our deregulated Src mutants in mammalian cells, we first performed a transcriptional assay using a Src-responsive 


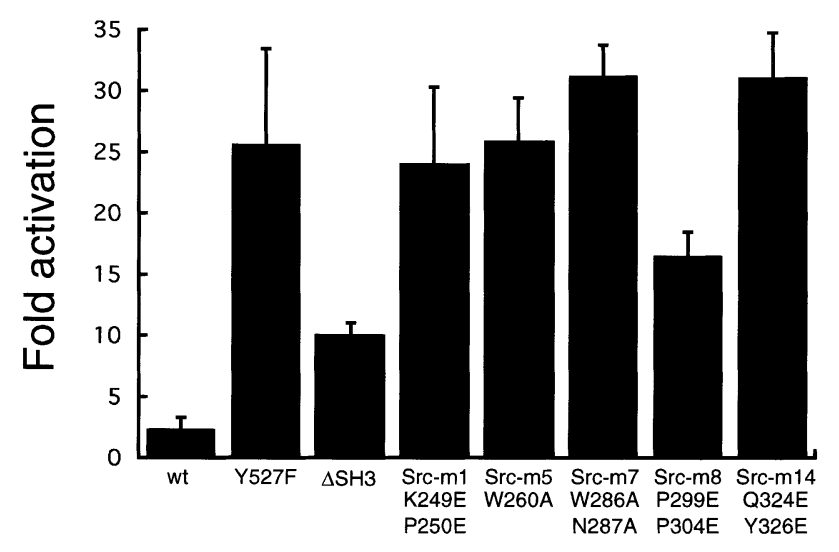

Fig. 6. Activity of Src mutants in an SRE-dependent luciferase transcriptional assay. Vector (pSGT) plasmid DNA, pSGT-c-Src or various pSGT-Src mutants were transiently transfected into human 293 cells together with an SRE-luciferase reporter construct. Fold activation is expressed as the ratio over the values obtained with the empty vector. Data are averages from two sets of experiments done in triplicate, and the values shown are means \pm standard deviation (SD).

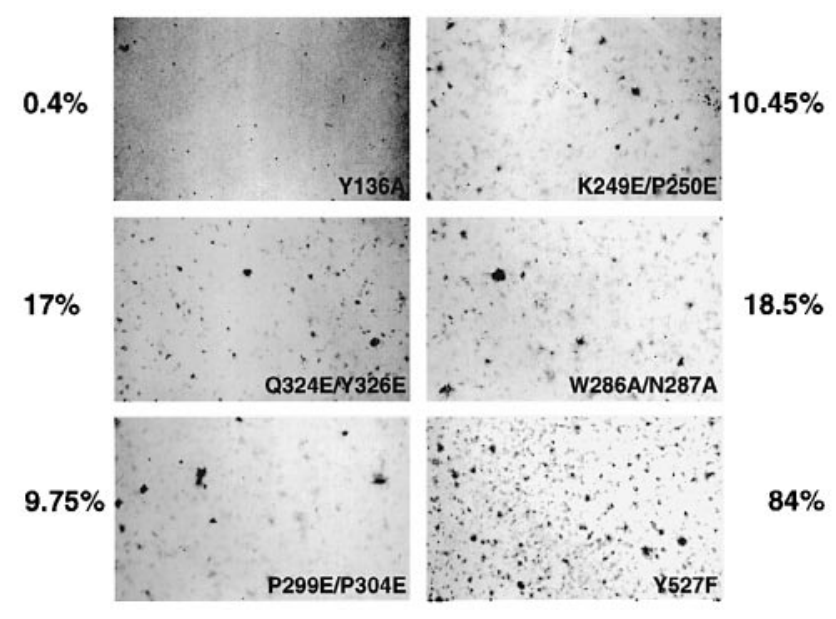

Fig. 7. Transformation activity of Src mutants. NIH-3T3 cells were transfected with SV40-driven Src expression vectors, as indicated, and a neomycin-resistant gene. Plates were stained with Giemsa 15 days later. Foci started to appear after 10 days in $5 \%$ calf serum and, 5 days later, the plates were stained. The numbers of neomycin-resistant colonies were counted on parallel plates 2 weeks after transfection. The percentage of foci was calculated as the ratio between the number of foci observed and the number of neomycin-resistant colonies. Shown is an average of three separate experiments done in duplicate.

promoter containing SREs that had been used previously to study Src activation in human cells (Alexandropoulos and Baltimore, 1996). The assay is highly sensitive to Src activity and addresses the ability of Src alleles to induce signalling to the nucleus. In this transient expression assay, all transfected proteins accumulated to comparable levels (data not shown). As previously reported, while c-Src expression in 293 cells only resulted in a 2-fold increase in luciferase activity over the vector controls, expression of Src-Y527F induced a 25-fold stimulation (Figure 6). The SH2-CD linker mutants Src-m1 (K249E, P250E) and Src-m5 (W260A) were as active as Src-Y527F. Also, the back of the kinase mutants Src-m7 (W286A,N287A) and Src-m14 (Q324E,Y326E) were as active as Src-Y527F. Src-m8 (P299E,P304E), bearing a mutation in the loop preceding the $\alpha \mathrm{C}$-helix, was completely deregulated in

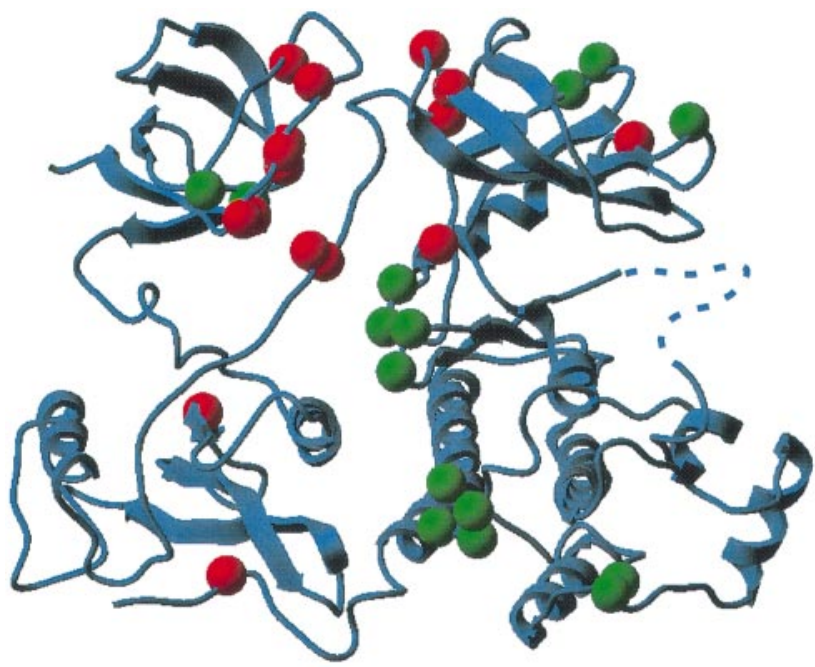

Fig. 8. Map of mutated sites on the three-dimensional structure of Src. Ribbon diagram of the crystal structure of regulated chicken c-Src. Residues that when mutated impair regulation strongly are shown as red spheres (Y90, Y92, S94, D99, W118, P133, Y136, R175, K249, P250, W260, W286, N287, P304, Q324, Y527). Mutations not affecting regulation are shown as green spheres (K104, E115, P299, R318, E320, S330, E331, R359, L360, P361, Q362, E396, N397, P484, P485). Mutations in the tail and in the SH3 and SH2 domains refer to previous work (Superti-Furga et al., 1993; Erpel et al., 1995).

the yeast assay but was weaker than Src-Y527F in the transcriptional assay. We scored no differences between the novel Src alleles and Src-Y527F in the ability to stimulate phosphorylation of endogenous proteins on tyrosine (data not shown). Together, these results indicate that Src mutants in the SH2-CD linker and in the linker interaction surface of the catalytic domain are deregulated in human cells.

To test the transformation potential of the various Src mutants, we performed a focus formation assay in NIH3T3 cells. Pools of neomycin-resistant colonies displayed very similar levels of Src protein expression (data not shown). The transformation efficiency of Src-Y527F was high $(84 \%)$, while that of c-Src was barely above the vector background. Also a Src allele bearing mutation of a tyrosine residue critical for the binding potential of the SH3 domain (Y136A) was indistinguishable from wildtype $\mathrm{Src}$ in this assay, in agreement with previous findings (Broome and Hunter, 1996). Likewise, a Src SH3 deletion mutant and a mutant bearing mutation of Pro133 in the SH3 domain (P133L; Erpel et al., 1995) were also unable to promote formation of foci (data not shown). Mutation of the lysine-proline motif in the linker (Src-m1) increased the transformation potential of Src $>20$-fold, but was still 8 -fold less active than Src-Y527F. The two catalytic domain mutants mapping to linker interaction sites, Src$\mathrm{m} 7$ and Src-m14, were capable of transforming NIH-3T3 cells more efficiently than the linker mutants. However, for both these mutants and the linker mutants, the transformation ability did not parallel the activity in the transcriptional assay. This suggests that the linker and its catalytic domain-binding surface are involved differently in the two processes. In contrast, we failed to detect significant qualitative or quantitative differences between Src-Y527F and the SH3 linker and catalytic domain Src mutants in their ability to generate phosphorylation of endogenous proteins on tyrosine (data not shown). This 
agrees with previous findings reporting that specific targets that may be important for transformation are not easily detected in analysis of bulk phosphorylation on tyrosine generated by Src (Seidel-Dugan et al., 1992; Erpel et al., 1995).

\section{Discussion}

The crystal structures of Src and Hck have shown that the regulated configuration of these kinases comprises an intricate set of intramolecular interactions involving the binding surfaces of the $\mathrm{SH} 2$ and $\mathrm{SH} 3$ domains (Sicheri et al., 1997; Williams et al., 1997; Xu et al., 1997). The SH2-CD linker sits between the SH3 domain-binding surface and the small lobe and interacts with both structures. We have found that mutation of the linker lysine and proline residues (K249, P250) interacting with the $\mathrm{SH} 3$ domain results in a completely deregulated form of Src and Lck, comparable with mutations in the regulatory tyrosine or in the $\mathrm{SH} 2$ domain phosphotyrosine-binding pocket. In agreement with this finding, mutation of Tyr136, interacting with Pro250 in the crystal structure, was previously found to be essential for regulation (Erpel et al., 1995). The interaction of the SH3 domain with the linker is relatively unspecific, involving hydrophobic residues of the linker and backbone interactions (Sicheri et al., 1997; Williams et al., 1997; Xu et al., 1997). Perhaps this explains regulation of Src mutants bearing the whole linker region of Lck (Src-m4) or parts of the Abl linker (Src-m2, Src-m3). Most probably, the ability to adopt a similar secondary structure in these mutants is preserved.

The $\alpha C$-helix is seen swung out in the structures of regulated Src and Hck, and located in a position that is very similar to the one observed in the structure of inactive CDK2 (De Bondt et al., 1993; Jeffrey et al., 1995). As a result, the conserved Glu310 in the $\alpha \mathrm{C}$-helix points outwards and does not form the salt bridge necessary to orient Lys 295 for optimal ATP binding. Regulation through orientation of the conserved glutamate is common to several other protein kinases (Taylor et al., 1993; Johnson et al., 1996). Our mutagenesis studies indicate that mutation of two proline residues in the $\beta 3 / \alpha \mathrm{C}$ loop can lead to Src (or Lck) forms that are completely refractory to regulation by C-terminal phosphorylation. All Src family kinases have at least one proline at one of the two positions. While mutation of Pro299 to Leu failed to activate Src, the mutation is found in viral Yes, where it may contribute to deregulation (Sudol et al., 1988). It may be that simultaneous mutation of the two proline residues into glutamic acid (the corresponding residues of Btk) relieves the loop and the following $\alpha \mathrm{C}$-helix from conformational constraints. Once free from these constraints, the $\alpha \mathrm{C}$-helix may find itself in the productive position more often. At the same time, movements of the $\alpha \mathrm{C}$-helix could result in impairment of linker and $\mathrm{SH} 3$ binding. We currently are testing this hypothesis. In any case, these results suggest that orientation of the $\alpha \mathrm{C}$-helix is a critical parameter for regulation of Src family kinases.

It is possible that mutations designed to increase flexibility of the $\beta 3 / \alpha C$ loop, such as removal of proline residues and introduction of glycine residues, may activate other regulated protein kinases.
Binding of the $\mathrm{SH} 2$ and $\mathrm{SH} 3$ domains in inactive Src and Hck appears to cause a rotation of the small lobe relative to the large lobe compared with the active form of the Lck catalytic domain (Yamaguchi and Hendrickson, 1996; Sicheri et al., 1997; Williams et al., 1997; Xu et al., 1997). These movements are accompanied by the mentioned displacement of the $\alpha \mathrm{C}$-helix and by restructuring of the activation loop (although only parts of the latter are seen in the Src and Hck structures), resulting in disablement of the active site (Sicheri et al., 1997; Williams et al., 1997; Xu et al., 1997). What is the role of the SH2-CD linker in this process? Our results support the possibility that the SH2-CD linker not only allows for SH3 domain binding to the small lobe of the catalytic domain, but may actively participate in displacement of the $\alpha \mathrm{C}$-helix. We believe that three interactions are candidates for this role.

Mutation of Q324 prevents regulation. This residue lies in the $\alpha \mathrm{C} / \beta 4$ loop following the $\alpha \mathrm{C}$-helix and undergoes multiple interactions with the linker. The $\alpha \mathrm{C} / \beta 4$ loop does not move between active and inactive positions of the $\alpha C$-helix (Williams et al., 1997). Q324 may be necessary to keep interaction of the linker with the helix fixed at one end, while other forces act elsewhere on the helix.

From the structure of regulated Hck, Kuriyan and colleagues have proposed that Trp260 may couple the conformation of the SH2-CD linker to inhibition of catalytic activity, by pushing downwards on the $\alpha \mathrm{C}$-helix (Sicheri et al., 1997). We have found that mutation of Trp260 to alanine clearly impairs regulation of Src, without preventing it completely. This result supports the proposed role. However, our results suggest that Trp260 may also have a structural role in Src, in agreement with its high degree of conservation among protein tyrosine kinases.

Insertion of a hydrophobic residue (Leu255 of the Src linker, Trp in Lck) in the hydrophobic pocket formed by the $\beta 2 / \beta 3$ loop and the $\alpha \mathrm{C} / \beta 4$ loop small lobe of the kinase domain may also be an active kinase inhibition mechanism (Williams et al., 1997). We have found that mutation of residues in the pocket prevents regulation, suggesting that interaction of the linker with this pocket is crucial. Comparison with the structure of the active Lck catalytic domain suggests the possibility that binding of Leu255 in Src may force displacement of Tyr326, resulting in dislocation of the $\alpha \mathrm{C}$-helix (Yamaguchi and Hendrickson, 1996; Williams et al., 1997). It is worth noting that the linker of Lck can substitute almost perfectly for the Src linker, implying that Trp can substitute for Leu255. Moreover, Trp286 forming one part of the pocket can be substituted for tyrosine, as in Lck. If indeed catalytic inhibition through hydrophobic insertion of residues between the $\beta 2 / \beta 3$ and $\alpha C / \beta 4$ loops is a valid mechanism for kinase regulation, it may become a valuable model for rationally designed kinase inhibitors.

Src mutants in the linker, or in the linker-interacting surface on the catalytic domain, are at least as active as Src-Y527F in mammalian cells. In contrast to c-Src and Src bearing deletion or point mutations in the SH3 domain, the Src linker mutants transform fibroblasts. However, their transformation efficiency is lower than that of SrcY527F. Likewise, the morphology of the transformed cells differs from Src-Y527-transformed cells. The relative low potency of transformation may explain the failure to detect 
mutations in the SH2-CD linker or in the catalytic domain linker-interacting surface in viral Src strains or in any spontaneous mutation of $\mathrm{c}-\mathrm{Src}$ cloned and passaged in Rous sarcoma virus (Jove and Hanafusa, 1987; Parsons and Weber, 1989).

One likely possibility is that the linker and the linkerinteracting surface on the catalytic domain are binding sites for proteins. In turn, such interactions may be necessary to localize Src at intracellular sites, such as focal adhesions. The ability to localize at focal adhesions is critical for the growth-promoting activities of Src (Liebl and Martin, 1992). Binding of proteins to the linker may be necessary to activate $\mathrm{Src}$ by favouring $\mathrm{SH} 3$ displacement and/or to prevent the SH3 domain from inhibiting catalytic activity. Src activators/substrates may interact with both the SH3 domain and the linker. Most Src substrates have $\mathrm{SH} 3$ domain binding potential, and some, like Cas, Efs/Sin, cortactin and p85-PI3K, also have an SH3 domain of their own (Brown and Cooper, 1996).

The coupling of SH3 and $\mathrm{SH} 2$ domain interactions to catalytic activity is a key feature of Src kinases. It allows for activation by SH2 and SH3 ligands (Liu et al., 1993; Alexandropoulos and Baltimore, 1996; Briggs et al., 1997; Moarefi et al., 1997) and ensures that the enzyme does not phosphorylate when not on the appropriate subcellular targets. This study provides functional evidence for an interplay between the SH2-CD linker and the $\alpha \mathrm{C}$-helix in the catalytic domain as the centrepiece of this regulatory coupling.

\section{Material and methods}

\section{Yeast strains and culture conditions}

All yeast studies employed the S.pombe strain SP200 $\left(h^{-s}\right.$ leul-32 ura 4 ade6-210). Growth conditions and media were according to Beach et al. (1985). Cells were grown either in full medium with addition of adenine (YEA) or minimal medium containing adenine (PMA) and leucine or uracil where appropriate. To repress the $n m t 1$ promoter, cells were kept in medium containing $4 \mu \mathrm{M}$ thiamine. Induction was done by washing the cells four times with PMA without thiamine. Growth curves were done in a gyratory shaker at $30^{\circ} \mathrm{C}$. Cell counts were determined under the microscope with a haemotocytometer or by optical density. Transformation of S.pombe was done by the lithium acetate (LiAc) method as described (Koegl et al., 1995).

\section{DNA constructs}

All Src alleles used in the yeast assays were cloned in a pRSP (SupertiFurga et al., 1993) vector version where the MluI site in the autonomously replicating sequence (ARS) has been destroyed by Klenow treatment. pRSP-c-Src, containing the chicken Src cDNA, and pAU-Csk, containing the human Csk cDNA, have been described previously (Superti-Furga et al., 1993). Mutants were generated by a two-step PCR approach using the $P f u$ polymerase (Stratagene). PCR fragments of the catalytic domain were cloned in the Src backbone using the MluI and Bsu36I sites. SH2$\mathrm{CD}$ linker mutants were cloned using the $\mathrm{NcoI}$ and $M l u \mathrm{I}$ sites. Kinase inactive versions of Src mutants were generated subsequently by PCR. All constructs were verified by sequencing of the relevant parts. At least two independently generated mutants for each allele were tested. Human Lck cDNA was cloned into pRSP. Lck mutants were generated by PCR. Expression of GST fusion proteins in S.pombe was achieved using pAG. pAG was constructed by cloning an $\mathrm{XbaI-BamHI}$ fragment containing the GST portion and a eukaryotic ribosomal binding site from pEBG (Tanaka et al., 1995; a kind gift of B.Mayer) into the S.pombe adh promoter-driven pADH-X expression vector (Superti-Furga et al., 1996). Different portions of kinase-inactive chicken Src were generated using PCR (Pfu polymerase) and cloned using BamHI and EcoRI in pAG. For inducible expression of Csk in yeast, we cloned the human Csk cDNA (Superti-Furga et al., 1996) into pRSP. The sequences of all oligonucleotides used and experimental details of the mutagenesis are available on request. For expression in mammalian cells, mutant $\mathrm{Src}$ alleles were cloned into the SV40 enhancer/promoter-containing pSGT (Erpel et al., 1995), a modified version of pSG5 (Green et al., 1988). The SRE-luciferase construct was a kind gift of K.Alexandropoulos and D.Baltimore (Alexandropoulos and Baltimore, 1996). pMexNeo was a kind gift of R.Klein (Martin-Zanca et al., 1989).

\section{Cell lysates}

Native protein extracts from S.pombe cells were produced by the lysis buffer-glass beads method as described previously (Superti-Furga et al., 1993). Small-scale denatured protein extracts were produced by short centrifugation in a microfuge tube of a constant number of cells (at least $10^{7}$ cells), resuspension of the pellet in $1 \times$ Laemmli sample buffer for $2 \mathrm{~min}$ at $95^{\circ} \mathrm{C}$ and another short centrifugation.

\section{Immunoblots}

Extracts $(40 \mu \mathrm{g})$ were analysed by SDS-PAGE as described (SupertiFurga et al., 1993), and probed with the following antibodies: (i) affinitypurified anti-Src monoclonal antibodies 2-17 (Microbiological Associates; 1:1500 dilution); (ii) rabbit antiserum anti-Src cst.1 (Kypta et al., 1990; 1:1000 dilution); (iii) rabbit antiserum anti-Csk Csk1 (Superti-Furga et al., 1993; 1:500); (iv) monoclonal anti-phosphotyrosine antibodies (UBI, 1:1500 dilution); and (v) rabbit polyclonal IgG antiLck (Santa Cruz Biotechnology; 1:750). The ECL chemiluminescent method (Amersham) was used for detection. When used for re-probing, membranes were stripped by shaking for $30 \mathrm{~min}$ at $50^{\circ} \mathrm{C}$ in stripping buffer (62.5 mM Tris pH 6.7/0.5\% SDS/100 mM $\beta$-mercaptoethanol), followed by extensive washes in PBS-T and re-blocking with bovine serum albumin (BSA).

\section{Transient transfection and luciferase assay}

293 cells $\left(2 \times 10^{6}\right.$ per $60 \mathrm{~mm}$ dish $)$, grown in Dulbecco's modified Eagles's medium (DMEM) containing 10\% fetal calf serum (FCS), were plated $16-20 \mathrm{~h}$ before transfection. DNA was transiently transfected by calcium phosphate precipitation (Ausubel et al., 1987). Two $\mu \mathrm{g}$ each of pSGT-expressing vector and of SRE-luciferase reporter DNA were used. At $18 \mathrm{~h}$ after transfection, the medium was replaced, and $24 \mathrm{~h}$ later the cells were lysed and extracts assayed for luciferase activity (Ausubel et al., 1987).

\section{Focus formation}

NIH-3T3 cells were grown in DMEM/10\% calf serum (CS). A total of $1.5 \times 10^{5}$ cells (per $100 \mathrm{~mm}$ dish) were plated $16-20 \mathrm{~h}$ before transfection, and transfected using calcium phosphate precipitation (Ausubel et al., 1987 ) with $0.5 \mu \mathrm{g}$ of linearized DNA per plate. In parallel, plates were co-transfected with $1 \mathrm{ng}$ of linearized pMEXNeo and $0.5 \mu \mathrm{g}$ each of pSGT vector. At $18 \mathrm{~h}$ after transfection, the cells were washed and grown in DMEM/5\% CS for 2 weeks. Transfection efficiency was determined as the number of colonies selected in medium containing G418 $(500 \mu \mathrm{g} / \mathrm{ml}) 15$ days after transfection.

\section{Acknowledgements}

We would like to thank Drs K.Alexandropoulos, D.Baltimore, B.J.Mayer and R.Klein for various helpful reagents; members of the Klein and Nebreda laboratories for suggestions; Daniela Barilá and Marina Moro for sharing ideas and reagents; and Sara A.Courtneidge, Rüdiger Klein and Michael Glotzer for critically reading the manuscript. We especially thank Sara A.Courtneidge for encouragement and suggestions throughout this study. S.G. and J.C.W. are supported by fellowships from the European Community and the A.von Humboldt Stiftung respectively.

\section{References}

Abagyan,R., Totrov,M. and Kuznetsov,D. (1994) ICM-a new method for protein modelling and design: application to docking and structure prediction from the distorted native conformation. J. Comput. Chem., 15, 488-506.

Alexandropoulos,K. and Baltimore,D. (1996) Coordinate activation of c-Src by $\mathrm{SH} 3$ and $\mathrm{SH} 2$ binding sites on a novel, p130 ${ }^{\text {Cas }}$-related protein, Sin. Genes Dev., 10, 1341-1355.

Ausubel,F.M., Brent,R., Kingston,R.E., Moore,D.D., Seidman,J.G., Smith,J.A. and Struhl,K. (1987) Current Protocols in Molecular Biology. John Wiley and Sons, New York. 
Beach,D., Rodgers,L. and Gould,J. (1985) ran1+ controls the transition from mitotic division to meiosis in fission yeast. Curr. Genet., 10, 297-311.

Briggs,S.D., Sharkey,M., Stevenson,M. and Smithgall,T.E. (1997) SH3mediated Hck tyrosine kinase activation and fibroblast transformation by the Nef protein of HIV-1. J. Biol. Chem., 272, 17899-17902.

Broome,M.A. and Hunter,T. (1996) Requirement for c-Src catalytic activity and the $\mathrm{SH} 3$ domain in platelet-derived growth factor $\mathrm{BB}$ and epidermal growth factor mitogenic signaling. J. Biol. Chem., 271 , $16798-16806$

Brown,M.T. and Cooper,J.A. (1996) Regulation, substrates and functions of src. Biochim. Biophys. Acta, 1287, 121-149.

Cohen,G.B., Ren,R. and Baltimore,D. (1995) Modular binding domains in signal transduction proteins. Cell, 80, 237-248.

De Bondt,H.L., Rosenblatt,J., Jancarik,J., Jones,H.D., Morgan,D.O. and Kim,S.-H. (1993) Crystal structure of cyclin-dependent kinase 2. Nature, 363, 595-602.

Erpel,T., Superti-Furga,G. and Courtneidge,S.A. (1995) Mutational analysis of the Src SH3 domain: the same residues of the ligand binding surface are important for intra- and inter-molecular interactions. EMBO J., 14, 963-975.

Erpel,T., Alonso,G., Roche,S. and Courtneidge,S.A. (1996) The Src SH3 domain is required for DNA synthesis induced by platelet-derived growth factor and epidermal frowth factor. J. Biol. Chem., 271, 16807-16812.

Green,S., Issemann,I. and Sheer,E. (1988) A versatile in vitro and in vivo eukaryotic expression vector for protein engineering. Nucleic Acids Res., 16, 369-370.

Hubbard,S.R., Wei,L., Ellis,L. and Hendrickson,W.A. (1994) Crystal structure of the tyrosine kinase domain of the insulin receptor. Nature, 372, 746-754

Hunter,T. (1987) A tail of two src's: mutatis mutandis. Cell, 49, 1-4.

Jeffrey,P.D., Russo,A.A., Polyak,K., Gibbs,E., Hurwitz,J., Massagué,J. and Pavletich,N.P. (1995) Mechanism of CDK activation revealed by the structure of a cyclinA-CDK2 complex. Nature, 376, 313-320.

Johnson,L.N., Noble,M.E.M. and Owen,D.J. (1996) Active and inactive protein kinases: structural basis for regulation. Cell, 85, 149-158.

Jove,R. and Hanafusa,H. (1987) Cell transformation by the viral src oncogene. Annu. Rev. Cell. Biol., 3, 31-56.

Koegl,M., Courtneidge,S.A. and Superti-Furga,G. (1995) Structural requirements for the efficient regulation of the Src protein tyrosine kinase by Csk. Oncogene, 11, 2317-2329.

Kypta,R.M., Goldberg,Y., Ulug,E.T., Courtneidge,S.A. (1990) Association between the PDGF receptor and members of the Src family of tyrosine kinases. Cell, 62, 481-492.

Liebl,E.C. and Martin,G.S. (1992) Intracellular targeting of pp60 $0^{\text {src }}$ expression: localization of $\mathrm{v}-\operatorname{src}$ to adhesion plaques is sufficient to transform chicken embryo fibroblasts. Oncogene, 7, 2417-2428.

Liu,X., Brodeur,S.R., Gish,G., Songyang,Z., Cantley,L.C., Laudano,A.P. and Pawson,T. (1993) Regulation of c-Src tyrosine kinase activity by the Src SH2 domain. Oncogene, 8, 1119-1126.

Lowell,C.A. and Soriano,P. (1996) Knockouts of Src-family kinases: stiff bones, wimpy $\mathrm{T}$ cells, and bad memories. Genes Dev., 10, 1845-1857.

Martin-Zanca,D., Oskam,R., Mitra,G., Copeland,T. and Barbacid,M. (1989) Molecular and biochemical characterization of the human trk proto-oncogene. Mol. Cell. Biol., 9, 24-33.

Matsuda,M., Mayer,B.J., Fukui,Y. and Hanafusa,H. (1990) Binding of transforming protein $\mathrm{P} 47^{\text {gag-crk }}$, to a broad range of phosphotyrosinecontaining proteins. Science, 248, 1537-1539.

Mayer,B.J. (1997) Clamping down on Src activity. Curr. Biol., 7, R295-R298.

Moarefi,I., LaFevre-Bernt,M., Sicheri,F., Huse,M., Lee,C.-H., Kuriyan,J. and Miller,W.T. (1997) Activation of the Src-family tyrosine kinase Hck by SH3 domain displacement. Nature, 385, 650-653.

Murphy,S.M., Bergman,M. and Morgan,D.O. (1993) Suppression of cSrc activity by C-terminal Src kinase involves the c-Src SH2 and $\mathrm{SH} 3$ domains: analysis with Saccharomyces cerevisiae. Mol. Cell. Biol., 13, 5290-5300

Nguyen,J.T. and Lim,W.A. (1997) How Src exercises self-restraint. Nature Struct. Biol., 4, 256-260.

Okada,M., Howell,B., Broome,M.A. and Cooper,J.A. (1993) Deletion of the SH3 domain of SRC interferes with regulation by the phosphorylated carboxy terminal tyrosine. J. Biol. Chem., 268 , $18070-18075$
Parsons,J.T. and Weber,M.J. (1989) Genetics of src: structure and functional organization of a protein tyrosine kinase. Curr. Top. Microbiol. Immunol., 147, 79-127.

Pawson,T. (1995) Protein modules and signalling networks. Nature, 373, 573-580.

Pawson,T. (1997) New impressions of Src and Hck. Nature, 385, 582-585.

Seidel-Dugan,C., Meyer,B., Thomas,S. and Brugge,J. (1992) Effects of $\mathrm{SH} 2$ and $\mathrm{SH} 3$ deletions on the functional activities of wild-type and transforming variants of c-Src. Mol. Cell. Biol. 12, 1835-1845.

Shalloway,D. and Taylor,S.J. (1997) Src: more than the sum of its parts. Trends Cell Biol., 7, 215-217.

Sicheri,F., Moarefi,I. and Kuriyan,J. (1997) Crystal structure of the Src family tyrosine kinase Hck. Nature, 385, 602-609.

Sudol,M., Kieswetter,C., Zhao,Y.-H., Dorai,T., Wang,L.-H. and Hanafusa,H. (1988) Nucleotide sequence of a cDNA for the chick yes proto-oncogene: comparison with the viral yes gene. Nucleic Acids Res., 16, 9876.

Superti-Furga,G. and Courtneidge,S.A. (1995) Structure-function relationships in Src family and related protein tyrosine kinases. BioEssays, 17, 321-330.

Superti-Furga,G. and Gonfloni,S. (1997) A crystal milestone: the structure of regulated Src. BioEssays, 19, 1-4.

Superti-Furga,G., Fumagalli,S., Koegl,M., Courtneidge,S.A. and Draetta,G. (1993) Csk inhibition of Src activity requires both the SH2 and SH3 domains of Src. EMBO J., 12, 2625-2634.

Superti-Furga,G., Jönsson,K. and Courtneidge,S.A. (1996) A functional screen in yeast for regulators and antagonizers of heterologous protein tyrosine kinases. Nature Biotechnol., 14, 600-605.

Tanaka,M., Gupta,R. and Mayer,B.J. (1995) Differential inhibition of signaling pathways by dominant-negative $\mathrm{SH} 2 / \mathrm{SH} 3$ adaptor proteins. Mol. Cell. Biol., 15, 6829-6837.

Taylor,S.S., Knighton,D.R., Zheng,J., Sowadski,J.M., Gibbs,C.S. and Zoller,M.J. (1993) A template for the protein kinase family. Trends Biochem. Sci., 18, 84-89.

Varmus,H. and Weinberg,R.A. (1993) Genes and the Biology of Cancer. Scientific American Library, New York

Weijland,A., Williams,J.C., Neubauer,G., Courtneidge,S.A., Wierenga, R.K. and Superti-Furga,G. (1997) Src regulated by C-terminal phosphorylation is monomeric. Proc. Natl Acad. Sci. USA, 94, 3590-3595.

Williams,J.C., Weijland,A., Gonfloni,S., Thompson,A., Courtneidge, S.A., Superti-Furga,G. and Wierenga,R.K. (1997) The $2.35 \AA$ crystal structure of the inactivated form of chicken Src: a dynamic molecule with multiple regulatory interactions. J. Mol. Biol., in press.

Xu,W., Harrison,S.C. and Eck,M.J. (1997) Three-dimensional structure of the tyrosine kinase c-Src. Nature, 385, 595-602.

Yamaguchi,H. and Hendrickson,W.A. (1996) Structural basis for activation of human lymphocyte kinase Lck upon tyrosine phosphorylation. Nature, 384, 484-489.

Received on August 28, 1997; revised on October 6, 1997 